\title{
Mudanças tecnológicas e políticas agroambientais no âmbito do estabelecimento da agricultura familiar
}

Jan Börner - Mestre pela Universidade Humboldt de Berlim.

\section{Resumo}

O artigo discute a agricultura da Zona Bragantina, antiga área de colonização na Amazônia e analisa as alternativas de mecanização do preparo de terra para substituir o sistema tradicional de corte e queima na produção de culturas temporárias e permanentes e procura aponta qual o impacto socioambiental da introdução de novas tecnologias agrícolas na região.
Palavras-chave

Degradação ambiental; agricultura familiar e produtividade agrícola.

\begin{abstract}
The article discusses the Zona Bragantina, an old area of colonization in the Amazonia and analysis the mechanization alternatives in preparing the land and to substitute the traditional system slash-and-burn process in the production of temporary and permanent cultures looking for indicate the socioambiental impact comprising the introduction of new agricultural technologies in the region.
\end{abstract}

\section{Keywords}

Environment dgradation; agriculture family the agriculture productivity. 


\section{INTRODUÇÃO}

Hoje tanto como no passado, ações governamentais e nãogovernamentais incentivam o uso de tecnologias na área da agricultura para atingir determinados objetivos de desenvolvimento. O que tende a mudar ao longo do tempo são as motivações que estão na base da formulação dos objetivos dessas ações, que podem ser, por exemplo, a maximização da produtividade agrícola, a conservação dos recursos naturais ou a erradicação da pobreza rural. Sem dúvida, é necessário levar em conta esses três eixos para formular estratégias de desenvolvimento sustentável.

Na agricultura da Zona Bragantina, tanto como em outras antigas áreas de colonização na Amazônia, a mecanização do preparo de terra chegou a ser uma alternativa forte para substituir o sistema tradicional de corte e queima na produção de culturas temporárias e permanentes. Vários governos locais investem em patrulhas mecanizadas para poder oferecer o serviço de preparo de terra mecanizado a um preço inferior ao praticado no mercado.

Segundo resultados do Projeto SHIFT-Capoeira, a mecanização convencional e o sistema tradicional de corte e queima contribuem para a degradação continuada da vegetação secundária (BAAR, 1997; DENICH et al., 2004). Essa vegetação representa um recurso natural de alto valor para a população rural, e as conseqüências ambientais de sua completa erradicação são desconhecidas.

A trituração mecanizada e diferentes formas de sistemas agroflorestais (SAF) são freqüentemente propostas como alternativas tecnológicas de impacto ambiental menor. Porém, no Nordeste paraense, elas ainda não saíram da fase de experimentação em poucos estabelecimentos agrícolas. Também são poucos os estudos (ver, por exemplo, WIESENMÜLLER, 1999) que analisam os impactos potenciais da mecanização convencional ou de outras formas do sistema tradicional sobre a renda e a cobertura vegetal dos estabelecimentos agrícolas da Zona Bragantina.

Conseqüentemente, este estudo tenta responder à seguinte pergunta, que é considerada central na tomada de decisão sobre a inovação tecnológica como estratégia de desenvolvimento sustentável: Qual o impacto socioambiental da introdução de uma tecnologia agrícola $x$ num determinado espaço geográfico e na presença de um desenvolvimento dinâmico?

Para dar uma resposta satisfatória à questão, precisa-se de informação sobre o estado atual do sistema socioambiental em questão e de uma avaliação ex ante dos impactos potenciais da promoção da mudança tecnológica.

Este artigo apresenta um resumo geral de um estudo que tentou 
elucidar alguns aspectos dessa questão por meio de uma metodologia quantitativa. Além de apresentar propostas para novas e as já existentes ações governamentais e não-governamentais na área da inovação tecnológica, este artigo tem três objetivos intermediários:

a. fornecer informações socioeconômicas gerais e representativas sobre o estado da pequena agricultura na Zona Bragantina;

b. desenvolver cenários do impacto de diferentes formas da mudança tecnológica em indicadores de bem-estar, qualidade de recursos naturais e desenvolvimento econômico rural;

c. desenvolver cenários do uso de instrumentos da política agrícola e ambiental para promover ou mitigar efeitos (positivos e negativos, respectivamente) da mudança tecnológica (pois ela também pode acontecer sem influência externa).

\section{DADOS E MÉTODOS}

O universo do estudo são as duas microrregiões Castanhal e Bragantina, excluindo as áreas do Salgado no oeste da região Bragantina (Figura 1). Com base na consulta de censos agrícolas e demográficos, na literatura secundária e no conhecimento local (por exemplo, de funcionários da EMATER e dos Sindicatos dos Trabalhadores Rurais), foram selecionados três municípios representativos com o objetivo de captar o maior nível de diversidade regional em termos de variação climática, sistemas de produção e desenvolvimento rural.

No período de outubro a dezembro de 2002, foram aplicados 270 questionários básicos em estabelecimentos agrícolas com menos de 200 hectares. Logo depois, escolheram-se duas parcelas de cada estabelecimento para obter dados detalhados de produção e qualidade de solo ${ }^{1}$. Para verificar os dados de produção, fez-se uma revisão extensa da documentação de experimentos agronômicos. Parte da análise descritiva foi também uma classificação de estabelecimentos a partir de características de intensificação, uso de tecnologia e região administrativa. Para cada um dos grupos representativos (I-IV) resultantes da classificação, desenvolveuse um modelo quantitativo de simulação no âmbito do estabelecimento, usando métodos de programação linear e não-linear. Uma discussão introdutória sobre as vantagens e os problemas da modelagem de sistemas complexos encontra-se em Sterman (1991). O método de programação linear é documentado em Hazell e Norton (1986), e os detalhes do modelo desenvolvido para este estudo estão descritos em Börner (2005).

\footnotetext{
A qualidade de solo foi determinada por meio de um bioassay a partir da amostragem de solo. 15 sementes de arroz foram plantadas com 4 repetições para cada parcela enumerada. A biomassa produzida após 3 semanas serviu como indicador de qualidade de solo.
} 


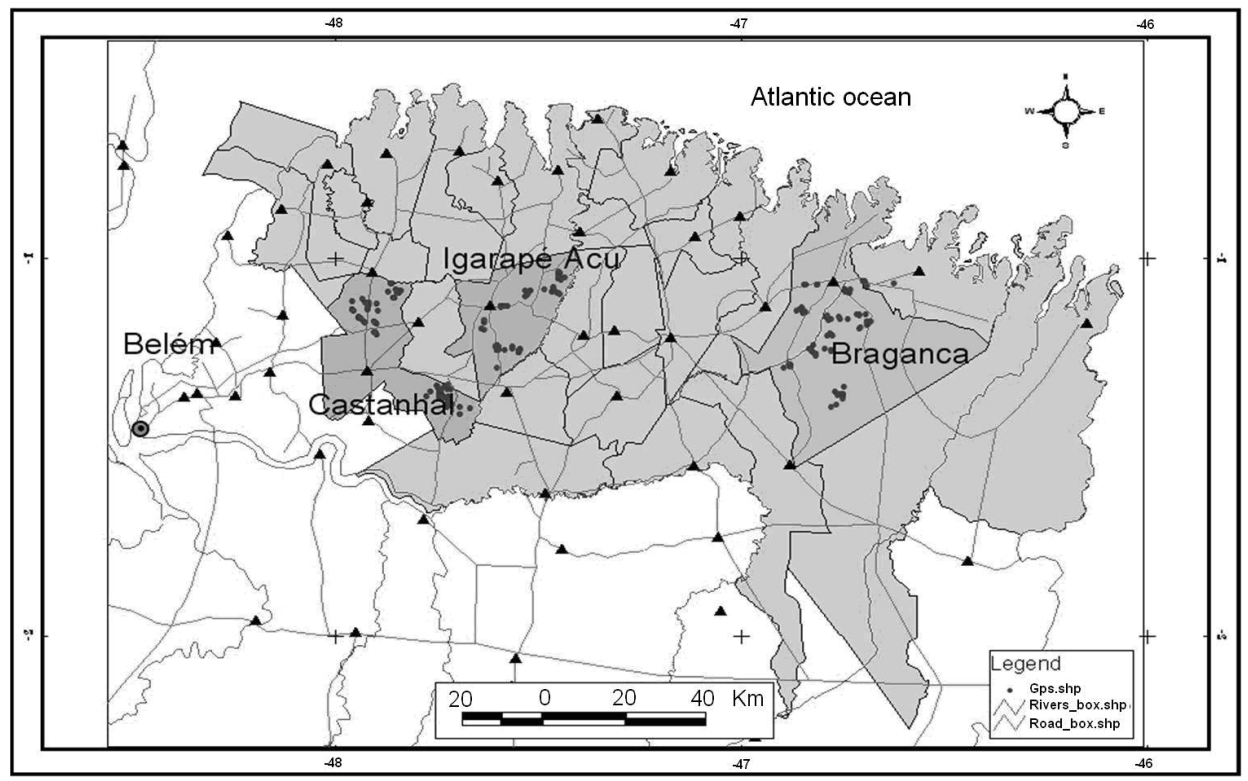

Figura 1: Microrregiões de Castanhal e Bragantina.

Para a interpretação dos resultados deste artigo, é necessário destacar as seguintes pressuposições em que se baseia o uso do método:

a. o objetivo principal do estabelecimento agrícola é a maximização da renda familiar e a minimização da variação potencial dessa renda (por exemplo, por meio da variação de preços e do rendimento físico na produção agrícola);

b. os pequenos agricultores não têm acesso ao mercado de terra;

c. o rendimento físico das culturas anuais da região é principalmente limitado pela concentração do elemento fósforo no solo.

Além disso, os seguintes fatos da realidade não foram considerados explicitamente porque sua inclusão no modelo requer uma representação menos detalhada dos processos produtivos e da dimensão temporal (o uso de recursos naturais renováveis) do problema em questão:

d. a interação das unidades familiares no mercado de trabalho e na difusão de informação;

e. efeitos de escala nos mercados locais e regionais de produtos agrícolas.

No que concerne aos pontos $b$ e $e$, foi testado o impacto da violação de uma ou de várias das pressuposições e concluiu-se que não há alteração na interpretação dos resultados. Entretanto, não foi possível simular

\footnotetext{
${ }^{2}$ A renda familiar é definida aqui como a renda líquida após a satisfação das necessidades básicas.
} 
satisfatoriamente o uso da terra e de tecnologia em aproximadamente 25\% dos estabelecimentos enumerados, a maioria caracterizada pela baixa integração comercial e pela baixa renda familiar. Acredita-se que a principal motivação no processo produtivo desses agricultores não é adequadamente representada pela pressuposição a. Para melhor representar essa motivação de forma quantitativa, seria necessário um estudo mais aprofundado do consumo e da aplicação de mão-de-obra familiar.

Tabela 1: Características socioeconômicas dos estabelecimentos pesquisados.

\begin{tabular}{|c|c|c|c|c|c|c|c|}
\hline & 1 Quartil & Quartil 3 & \begin{tabular}{l|l|l} 
Quartil & 4
\end{tabular} & Quartil & Média & Censo & Gini \\
\hline Renda líquida per capita & 285 & 792 & 1651 & 7599 & 2585 & & 0,66 \\
\hline \multicolumn{8}{|c|}{ Renda per capita proveniente do estabelecimento } \\
\hline Produção vegetal (R\$/ano) & 158 & 500 & 1083 & 4844 & 1649 & & \\
\hline Produção de animais (R\$/ano) & 11 & -8 & 24 & 1944 & 495 & & \\
\hline Total (R\$/ano) & 169 & 493 & 1107 & 6788 & 2143 & 863 & \\
\hline Percentagem comercializada (\%) & 46 & 60 & 63 & 73 & 60 & & \\
\hline \multicolumn{8}{|c|}{ Renda proveniente de atividades realizadas fora do estabelecimento (R\$/ano) } \\
\hline Empregos não-agrícolas & 49 & 103 & 166 & 342 & 165 & & \\
\hline Assistência familiar & 4 & 6 & 9 & 8 & 7 & & \\
\hline Bolsa Escola & 10 & 8 & 7 & 5 & 7 & & \\
\hline ICSS & 33 & 173 & 334 & 427 & 241 & & \\
\hline Empregos agrícolas & 21 & 10 & 28 & 29 & 22 & & \\
\hline \multicolumn{8}{|l|}{ Recursos físicos } \\
\hline Tamanho do lote (ha) & 17,4 & 19,6 & 15,8 & 31,9 & 21,2 & 15 & 0,53 \\
\hline $\begin{array}{l}\text { Capoeiras grossas em \% do lote } \\
\text { (idade média) }\end{array}$ & $13,6(12)$ & $14,4(13)$ & $14,2(15)$ & $19,6(19)$ & $5,4(17)$ & & \\
\hline \multicolumn{8}{|l|}{ Capoeiras finas em \% do lote } \\
\hline Área em produção (ha) & 2,4 & 3,1 & 3,4 & 6,7 & 3,9 & 3,5 & \\
\hline $\begin{array}{l}\text { Qualidade de solo } \\
\text { Índice de bem-estar (bens }\end{array}$ & 2,24 & 2,05 & 2,13 & 2,09 & 2,29 & & \\
\hline $\begin{array}{l}\text { agrícolas) } \\
\text { Índice de bem-estar (bens }\end{array}$ & $-0,91$ & $-0,42$ & 0,06 & 1,28 & 0 & & \\
\hline domésticos) & $-1,43$ & $-0,04$ & 0,15 & 1,33 & 0 & & \\
\hline \multicolumn{8}{|l|}{ Mão-de-obra } \\
\hline \multicolumn{8}{|l|}{ Mão-de-obra familiar (adulto } \\
\hline $\begin{array}{l}\text { Mão-de-obra contratada (homem } \\
\text { dias/ano) }\end{array}$ & 29 & 40 & 47 & 115 & 63 & & \\
\hline \multicolumn{8}{|l|}{ Capital social/político } \\
\hline \multicolumn{8}{|l|}{ Participação em } \\
\hline associações/sindicatos (\%) & 38 & 56 & 66 & 81 & 60 & & \\
\hline \multicolumn{8}{|l|}{ Composição demográfica } \\
\hline Tamanho da família & 7,5 & 6,3 & 6,2 & 4,6 & 6,2 & 4,7 & \\
\hline Número de crianças (< 16 anos) & 3,9 & 2,3 & 2,1 & 1,4 & 2,4 & & \\
\hline \multicolumn{8}{|l|}{ Nível de educação do chefe da } \\
\hline família (anos) & 2,5 & 2,9 & 2,3 & 4 & 2,9 & & \\
\hline \multicolumn{8}{|l|}{ Município } \\
\hline Castanhal & 11 & 19 & 24 & 36 & 90 & & \\
\hline Igarapé-Açu & 18 & 25 & 25 & 22 & 90 & & \\
\hline Bragança & 39 & 24 & 18 & 10 & 91 & & \\
\hline Total & 68 & 68 & 67 & 68 & 271 & & \\
\hline
\end{tabular}

Fonte: Pesquisa de campo Shift/Naea (2002-2003); IBGE. Censo agrícola 1995-1996. 


\section{RESULTADOS}

\subsection{Análise descritiva}

A Tabela 1 apresenta características selecionadas dos estabelecimentos enumerados para diferentes classes de renda líquida familiar per capita. O quadro geral obviamente confirma a hipótese existente sobre um gradiente de desenvolvimento rural na região Bragantina. Estabelecimentos a oeste (Castanhal) parecem ter um nível mais elevado de qualidade de vida (renda, educação, bens duráveis) do que a leste (Bragança) da região. Também no oeste da região Bragantina concentram-se estabelecimentos que utilizam tecnologias mais modernas de produção agrícola, por exemplo, mecanização do preparo de terra para a produção e beneficiamento de mandioca para a produção intensiva de culturas permanentes. A maioria da renda familiar, em todas as categorias, é proveniente da agricultura; mesmo assim se observa que uma porcentagem maior da renda de famílias desfavorecidas vem de atividades realizadas fora da agricultura ou da assistência pública. Quanto à assistência pública, o sistema de aposentadoria rural alcança mais famílias no oeste do que no leste da região Bragantina.

Uma constatação interessante é a distribuição relativamente igual de velhas e jovens florestas secundárias ou capoeiras. Embora pareça que estabelecimentos com renda maior conservam uma porcentagem maior de capoeiras velhas, essa diferença não é estatisticamente significante. Isso contradiz a idéia notória de que agricultores menos favorecidos caracterizam-se pelo uso excessivo de recursos naturais.

À primeira vista poder-se-ia concluir que a qualidade de solo é também uniformemente distribuída entre os estabelecimentos. Porém, classificando-se os estabelecimentos com base em indicadores de intensificação de uso da terra, por exemplo, tempo médio de pousio ou uso de fertilizantes químicos e maquinaria, chega-se a um quadro diferente. Nesse caso, os dados sugerem uma menor qualidade natural em solos que estão mais intensamente cultivados, embora os rendimentos físicos da produção agrícola sejam mais altos. Ao mesmo tempo, observase que os rendimentos em sistemas menos intensificados são baixos, embora a qualidade natural dos solos seja mais alta (Tabela 2). Isso mostra que, até um determinado ponto, existe um potencial para substituir capital natural (qualidade natural do solo por meio de prolongados ciclos de pousio) e capital físico (aplicação de fertilizantes químicos e orgânicos, maquinaria e curtos ciclos de pousio). É difícil determinar os limites desse potencial, pois eles dependem de fatores que variam em função de dimensões temporais e espaciais e do comportamento humano.

Conseqüentemente, os resultados da modelagem apresentados abaixo precisam ser interpretados com cuidado. O uso de uma tecnologia 
pode parecer vantajoso do ponto de vista econômico, mas a falta de conhecimento sobre o impacto ambiental a longo prazo impede a sua recomendação sem restrições adicionais.

Tabela 2: Intensidade do uso de terra, rendimento físico e qualidade natural do solo.

\begin{tabular}{lrrrr}
\hline & Grupo I & Grupo II & Grupo III & Grupo IV \\
\hline Intensidade de uso de terra & 42 & 33 & 23 & 19 \\
Farinha de mandioca kg/ha & 4.456 & 4.658 & 3.611 & 3.106 \\
Qualidade do solo & 2,15 & 2,12 & 2,31 & 3,26 \\
\hline
\end{tabular}

Fonte: Pesquisa de campo Shift/Naea (2002-2003) e Fator Ruthenberg (RUTHENBERG, 1980).

\subsection{Modelagem e simulação}

\subsubsection{Validação}

O primeiro passo para a validação de um resultado de simulação é a comparação com os dados observados (KRUSEMAN, 2000). Para medir impactos socioambientais, o modelo oferece três indicadores simples de sustentabilidade: o indicador de bem-estar é a renda familiar anual e a sua variação; o indicador de crescimento da economia local é o número de dias de mão-de-obra contratada; o indicador de impacto ambiental é o uso da terra para a produção agrícola e o pousio, bem como a composição etária da capoeira.

Uma simulação satisfatória da situação atual deveria reproduzir esses indicadores no ano-base (2001-2002), e a evolução dos indicadores ao longo do tempo deveria estar de acordo com observações do passado. Um indicador de validez da parte biofísica do modelo é o valor implícito da vegetação secundária, sendo ela a restrição principal de produtividade na produção tradicional (corte e queima) de culturas anuais. O processo de otimização tem como resultado o valor monetário de um hectare de capoeira em diferentes idades. Esse valor deveria corresponder ao valor estimado em Mendoza-Escalante (2005) por meio de métodos estatísticos.

Tabela 3: Comparação do uso da terra (valor da capoeira) observado (estimado) e simulado.

\begin{tabular}{|c|c|c|}
\hline Indicadores & $\begin{array}{l}\text { Pesquisa de campo (área } \\
\text { em \% do tamanho do lote) }\end{array}$ & $\begin{array}{l}\text { Simulação-base (área em \% do } \\
\text { tamanho do lote) }\end{array}$ \\
\hline Culturas anuais & 15 & 16,6 \\
\hline Culturas permanentes & 5,2 & 5,8 \\
\hline Capoeira & 63,4 & 58,7 \\
\hline Pastagem & 5,9 & 5,9 \\
\hline \multirow[t]{2}{*}{ Não usada } & 10,5 & 12,4 \\
\hline & Mendoza-Escalante (2005) & $\begin{array}{c}\text { Simulação-base com exclusão } \\
\text { da produção de culturas } \\
\text { permanentes }\end{array}$ \\
\hline
\end{tabular}


A Tabela 3 compara resultados da modelagem com observações empíricas e o valor estimado da capoeira, respectivamente. Da mesma forma, comparam-se resultados da modelagem com observações do passado na Tabela 4. Durante os primeiros 10 anos, as tendências dos indicadores resultantes da simulação correspondem às observações do passado de 10 agricultores representativos para os grupos I e II da classificação (ver dados e métodos).

Tabela 4: Tendências de curto prazo estimadas na simulação-base.

\begin{tabular}{l|r|c}
\hline \multirow{2}{*}{ Indicadores } & \multicolumn{2}{|c}{ Resultado de regressão } \\
\cline { 2 - 3 } & inclinação & R-quadrado \\
\hline Idade capoeira (anos) & $-0,309^{*}$ & 0,96 \\
Área em capoeira (ha) & $-0,083^{*}$ & 0,65 \\
Área em produção (ha) & $0,069^{*}$ & 0,6 \\
\hline
\end{tabular}

* Significante (95\%).

As tabelas mostram que o modelo reproduziu satisfatoriamente os valores do uso da terra no ano da pesquisa de campo. Também as tendências temporais observadas estão aproximadas na simulação. O valor implícito da capoeira é ligeiramente inferior ao estimado por Mendoza-Escalante (2005), o que se deve à simplificação dos sistemas de produção representados no modelo. Com isso, conclui-se que o modelo representa um instrumento adequado para atender os objetivos deste estudo.

\subsubsection{Simulação-base}

A simulação-base é uma simulação que pressupõe que os fatores considerados exógenos ao estabelecimento - por exemplo, preços, assistência pública etc. - continuam iguais aos do ano-base (2001-2002). A Tabela 5 mostra as tendências dos indicadores de sustentabilidade durante os 25 anos da simulação. Segundo o modelo, a renda líquida familiar permanece constante durante o horizonte da simulação. Ao mesmo tempo, observa-se um declínio significante da idade média da capoeira e, com isso, uma queda considerável de carbono seqüestrado pela biomassa viva do estabelecimento.

O resultado da menor idade média da capoeira é uma queda de produtividade na produção de mandioca no sistema tradicional. Isso confirma uma das hipóteses do Projeto SHIFT-Capoeira sobre o declínio da produtividade do sistema de corte e queima. Porém, com o declínio da produtividade na produção de mandioca, aumenta a produção de feijão. O feijão, como muitas culturas permanentes, precisa de fertilizantes químicos. A introdução dessas culturas permite, até um determinado grau, desatrelar a produção agrícola do sistema de pousio. Uma comparação de simulações com e sem acesso à produção de culturas permanentes mostra que a idade média da capoeira assim como a área 
em vegetação secundária diminuem de forma mais acentuada e rápida na ausência de culturas permanentes. Isso se deve ao fato de que a demanda de mão-de-obra na produção de maracujá ou pimenta é muito maior do que na produção de culturas anuais. O preparo da terra para culturas anuais coincide com a colheita das culturas permanentes, assim como uma área menor é preparada em sistemas mistos.

Tabela 5: Tendências de curto prazo em indicadores de sustentabilidade estimadas da simulação-base.

\begin{tabular}{lc|r}
\hline & Inclinação & R-quadrado \\
\hline Bem-estar & & 0 \\
$\begin{array}{l}\text { Renda líquida familiar (R\$) } \\
\text { Meio ambiente }\end{array}$ & 3,396 & 0,56 \\
Idade média da capoeira (anos) & $-0,078 * *$ & 0,08 \\
Area em capoeira produtiva (ha) & $-0,01$ & 0,61 \\
Carbono total (t) & $-3,843 * *$ & 0,06 \\
Economia rural & & $-0,198$ \\
Mão-de-obra contratada (dias/ano) & & 0,13 \\
Produção & $-15,851 *$ & 0,24 \\
Valor anual da produção de farinha de mandioca (R\$) & $3,63 *$ & \\
Valor anual da produção de feijão (R\$) & & \\
\hline
\end{tabular}

$N=25, *$ Significante $90 \% . e^{* *}$ Significante $99 \%$.

A simulação-base mostra a importância de uma visão integrada do estabelecimento agrícola. No presente caso, observa-se que a introdução de culturas de produção intensiva - por exemplo, maracujá, pimentado-reino - contribui para a conservação da vegetação secundária. Porém, também o sistema misto não garante uma sustentabilidade ecológica no sentido de manter os indicadores ambientais no nível atual.

\subsubsection{Análise de sensitividade}

Uma análise de sensitividade é uma série de simulações experimentais em que variam as condições iniciais (por exemplo, áreas em pousio e cultivadas no primeiro ano) ou os parâmetros (por exemplo, o grau de aversão à variação da renda familiar ou os preços de produtos agrícolas) da simulação-base.

O modelo mostra que a presença de grandes áreas em capoeiras velhas no estabelecimento aumenta a área de culturas anuais em relação às culturas permanentes. Isso é resultado da maior produtividade do sistema tradicional na presença de uma grande quantidade de biomassa, que se transforma em nutrientes após a queima.

O papel da aversão ao risco é crucial na geração de resultados acerca da situação observada (Figuras 2 e 3). As figuras mostram uma série de simulações em que variam as preferências do "estabelecimento modelo" em relação à maximização da renda familiar e à minimização do risco. Pressupondo-se que o interesse principal do agricultor seja a renda média mais alta possível, ele se localiza no ponto mais alto da 
curva côncava na Figura 3 (ou à esquerda, Figura 2), por meio da especialização em culturas permanentes.

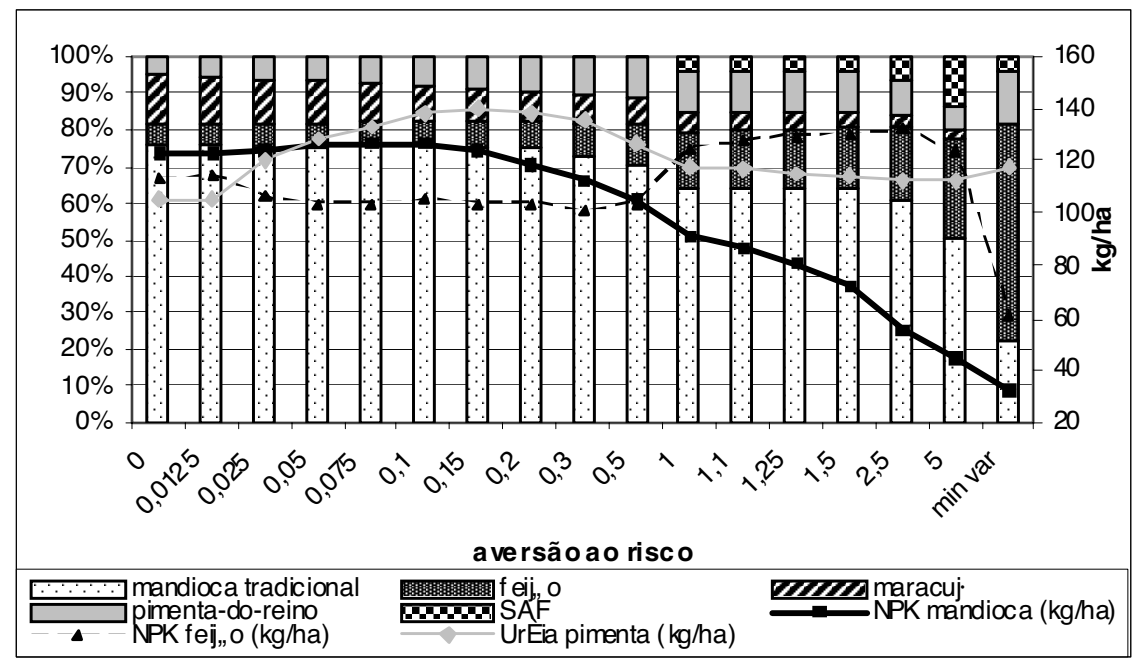

Figura 2: Aversão ao risco, uso da terra e fertilizantes químicos.

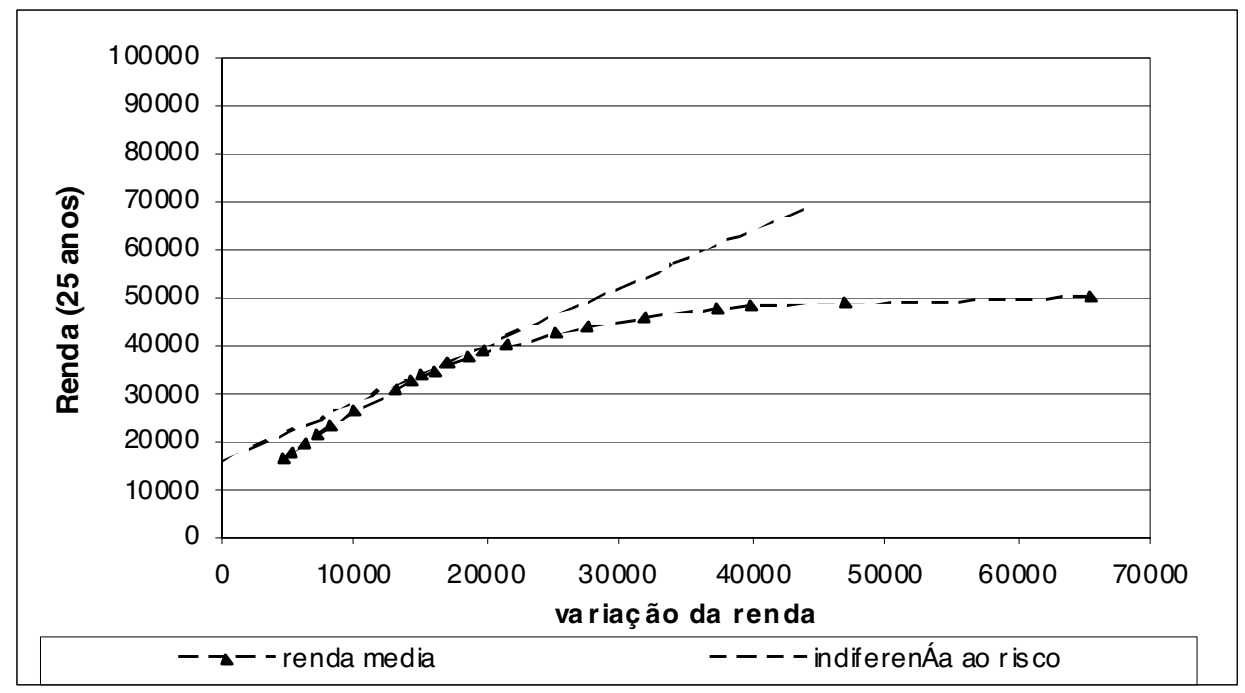

Figura 3: Uso da terra e fertilizante.

Um agricultor menos atrevido aceitaria uma renda média mais baixa e ao mesmo tempo mais estável por meio da diversificação da produção. Interessante é o que o modelo indica em relação ao grau de intensificação da produção por meio do uso de fertilizantes químicos. Levando em conta a variação de preços e do rendimento físico das culturas agrícolas, existe a possibilidade de chegar a uma renda mais estável por meio da intensificação ou extensificação da produção, dependendo da cultura e do grau de aversão ao risco. O aumento da aplicação de fertilizantes na produção da pimenta-do-reino pode diminuir a variação da renda em níveis moderados de aversão (Figura 2). 
Entretanto, em culturas anuais, a aversão ao risco sempre coincide com uma aplicação reduzida de fertilizantes.

A Tabela 6 mostra elasticidades da demanda (de fatores de produção) e da oferta (de produtos agrícolas). Os números na tabela representam o incremento percentual de 1\% no preço dos itens no cabeçalho da tabela. Uma sensitividade alta da variável, indica valores acima de (1) e vice-versa.

Tabela 6:Elasticidades da oferta de produtos e demanda de insumos agrícolas.

\begin{tabular}{|c|c|c|c|c|c|c|}
\hline \multirow[b]{2}{*}{ Indicador } & \multicolumn{6}{|c|}{ Preços } \\
\hline & $\begin{array}{l}\text { Fertilizantes } \\
\text { químicos }\end{array}$ & Diária & $\begin{array}{c}\text { Farinha de } \\
\text { mandioca }\end{array}$ & Feijão & $\begin{array}{l}\text { Pimenta- } \\
\text { do-reino }\end{array}$ & Maracujá \\
\hline Mão-de-obra contratada & $-3,16$ & $-4,14$ & 1,22 & 0,78 & 5,99 & $\overline{2,6}$ \\
\hline Mão-de-obra vendida & 1,99 & 2,13 & $-0,45$ & $-0,61$ & $-2,08$ & $-0,84$ \\
\hline Feijão vendido & $-1,04$ & $-1,27$ & 1,19 & 0,96 & $-0,14$ & $-1,61$ \\
\hline Farinha de mandioca vendida & 0,03 & $-0,12$ & 0,41 & 0,01 & $-0,43$ & $-0,04$ \\
\hline Pimenta-do-reino vendida & $-0,44$ & $-0,44$ & $-0,26$ & 0,06 & 0,64 & 0,43 \\
\hline $\begin{array}{l}\text { Maracujá vendido } \\
\text { Valor da produção de culturas }\end{array}$ & $-0,53$ & $-0,44$ & $-0,22$ & 0,14 & 1,38 & 1,98 \\
\hline $\begin{array}{l}\text { anuais } \\
\text { Valor da produção de culturas }\end{array}$ & $-0,14$ & $-0,28$ & 1,33 & 0,35 & $-0,41$ & $-0,73$ \\
\hline permanentes & $-0,47$ & $-0,44$ & $-0,25$ & 0,09 & 1,6 & 0,48 \\
\hline Valor da produção vegetal total & $-0,38$ & $-0,4$ & 0,16 & 0,15 & 1,08 & 0,36 \\
\hline
\end{tabular}

O conceito da elasticidade ajuda na determinação do impacto potencial de mudanças econômicas e políticas de preço e pode elucidar inter-relações de produção em sistemas mistos que não são óbvias. Um exemplo: o preço de fertilizantes químicos mostrou uma tendência de aumento no período de 2000 a 2002 (pesquisa de campo SHIFT/NAEA, 2002-2003). O modelo sugere que a continuação dessa tendência teria impactos fortes na demanda e na oferta de mão-de-obra, pois ela afetaria negativamente a produtividade da produção de culturas permanentes e, com isso, o custo de oportunidade do trabalho externo. Essa tendência quase não tem impacto na produção de farinha de mandioca, pois na maioria dos casos ela é produzida sem uso de fertilizantes.

\subsubsection{Cenários de mudanças tecnológicas}

A Figura 4 apresenta os impactos de diferentes cenários de mudanças tecnológicas nos indicadores de sustentabilidade no âmbito do estabelecimento, medidos em mudanças percentuais comparados com a simulação-base. As alternativas tecnológicas consideradas são: o sistema tradicional de corte e queima com fertilização química ( $\left.C \& Q_{3}+F\right)$, a trituração mecanizada oferecida a 30/10\% dos custos estimados ${ }^{3}$ (30/10\% T), a mecanização convencional com arado ${ }^{4}(\mathrm{M})$ e um sistema agroflorestal

\footnotetext{
${ }^{3}$ O custo médio usado aqui é R\$ 860/ha (para uma estimativa de custo para o serviço de trituração mecanizada, ver Bevilacha, neste volume).

${ }^{4} \mathrm{O}$ custo médio da mecanização usado aqui é R\$180/ha.
} 
simples, com beneficiamento de frutas (SAF). A redução do custo da trituração foi necessária para induzir a sua adoção como alternativa de preparo da terra no modelo, o que indica que um refinamento tecnológico adicional é crucial para atingir uma maior competitividade econômica da tecnologia. A alternativa "corte e queima com fertilização" representa os custos reais de qualquer sistema mecanizado que depende de fertilização e precisa ser incluída numa análise econômica consistente.

Os resultados apresentados na Figura 4 mostram que todas as alternativas tecnológicas podem contribuir positivamente para a renda familiar e o desenvolvimento rural por meio da geração de novas oportunidades de emprego. Porém, o impacto de mudanças tecnológicas nos indicadores ecológicos muitas vezes é negativo. Com exceção do sistema agroflorestal, todas as mudanças tecnológicas conduzem à degradação da vegetação secundária em termos de uma redução da idade média (e diversidade de espécies arbóreas (BAAR, 1997). A mecanização convencional, mais do que as outras alternativas, também aumenta a área de produção devido ao alto aproveitamento da tecnologia, pelo menos nos primeiros anos após sua introdução.

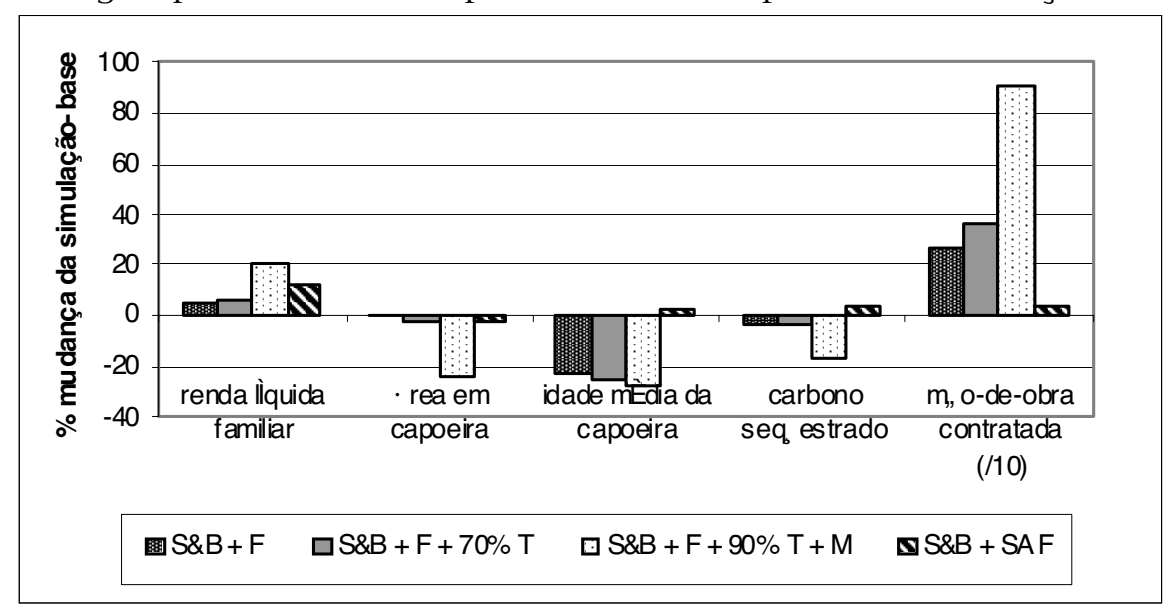

Figura 4: Cenários de mudanças tecnológicas.

Além disso, os cenários de mudanças tecnológicas mostram que a introdução do preparo de terra mecanizado, sem medidas adicionais, não contribuirá para diminuir o uso de corte e queima. Quando há acesso à mecanização convencional e à trituração, o modelo mostra que a área com culturas anuais aumenta 74\% em comparação à simulação-base. Em média, 54\% da área continuam no sistema tradicional, porque a mecanização simplesmente aumenta a capacidade do estabelecimento de preparar área numa época de alta demanda de mão-de-obra.

\subsubsection{Cenários de políticas agroambientais}

A Tabela 7 mostra quatro simulações da implementação de diferentes políticas agroambientais. 
Tabela 7: Cenários de políticas agroambientais.

\begin{tabular}{|c|c|c|c|c|c|c|c|c|c|c|c|c|}
\hline \multirow[t]{2}{*}{ Cenários } & \multicolumn{2}{|c|}{$\begin{array}{l}\text { Renda líquida } \\
\text { familiar } \mathrm{R} \$\end{array}$} & \multicolumn{2}{|c|}{ Gastos anuais $\mathrm{R} \$$} & \multicolumn{2}{|c|}{$\begin{array}{c}\text { Valor da produção } \\
\text { de culturas anuais } \\
\text { em } \mathrm{R} \$\end{array}$} & \multicolumn{2}{|c|}{$\begin{array}{c}\text { Valor da produção } \\
\text { de culturas } \\
\text { permanentes em } \mathrm{R} \$\end{array}$} & \multicolumn{2}{|c|}{$\begin{array}{c}\text { Mão-de-obra } \\
\text { contratada em } \\
\text { dias/ano }\end{array}$} & \multicolumn{2}{|c|}{$\begin{array}{c}\text { Mão-de-obra } \\
\text { vendida em } \\
\text { dias/ano }\end{array}$} \\
\hline & Total & $? \mathrm{em} \%$ & Total & $? \mathrm{em} \%$ & \begin{tabular}{|l|} 
Total \\
\end{tabular} & $? \mathrm{em} \%$ & Total & ? em \% & Total & $? \mathrm{em} \%$ & Total & $? \mathrm{em} \%$ \\
\hline 1. Proambiente & 1772 & -56 & 8341 & 2 & 4891 & 87 & 1829 & -76 & 2 & -73 & 191 & 129 \\
\hline $\begin{array}{l}\text { 2. Proambiente modificado } \\
\text { 3. Pagamentos de conservação }\end{array}$ & 3690 & -9 & 9340 & 14 & 5167 & 98 & 5711 & -25 & 8 & 9 & 22 & -74 \\
\hline $\begin{array}{l}\text { (R\$160,00/ha) } \\
\text { 4. Imposto sobre corte e queima }\end{array}$ & 5103 & 26 & 8689 & 7 & 8014 & 207 & 3941 & -48 & 43 & 523 & 7 & -92 \\
\hline \multirow[t]{3}{*}{ (R\$ 300,00/ha) } & 4449 & 9 & 9369 & 15 & 8279 & 217 & 4062 & -47 & 66 & 846 & 6 & -93 \\
\hline & \multicolumn{2}{|c|}{$\begin{array}{c}\text { Área em } \\
\text { culturas anuais } \\
\text { em há } \\
\end{array}$} & \multicolumn{2}{|c|}{$\begin{array}{c}\text { Área em culturas } \\
\text { permanentes } \\
\text { intensivas em há }\end{array}$} & \multicolumn{2}{|c|}{$\begin{array}{c}\text { Área em culturas } \\
\text { permanentes } \\
\text { extensivas em há }\end{array}$} & \multicolumn{2}{|c|}{ Área em capoeira } & \multicolumn{2}{|c|}{$\begin{array}{l}\text { Idade média da } \\
\text { capoeira }\end{array}$} & \multicolumn{2}{|c|}{$\begin{array}{c}\text { Área em } \\
\text { pastagens em ha }\end{array}$} \\
\hline & Total & $? \mathrm{em} \%$ & Total & $? \mathrm{em} \%$ & Total & ? em \% & Total & $? \mathrm{em} \%$ & Total & $? \mathrm{em} \%$ & Total & $? \mathrm{em} \%$ \\
\hline 1. Proambiente & 3,6 & 29 & 0,2 & -84 & 0,1 & 163 & 9 & 2 & 5 & 46 & 1 & 1 \\
\hline $\begin{array}{l}\text { 2. Proambiente modificado } \\
\text { 3. Pagamentos de conservação }\end{array}$ & 3,9 & 40 & 0,6 & -39 & 0,2 & 546 & 9 & -4 & 5 & 34 & 1 & -4 \\
\hline $\begin{array}{l}\text { (R\$ } 160,00 / \text { ha) } \\
\text { 4. Imposto sobre corte e queima }\end{array}$ & 4,4 & 57 & 0,4 & -61 & 0 & -100 & 7 & -19 & 11 & 196 & 1 & -44 \\
\hline \multirow[t]{3}{*}{ (R\$300,00/ha) } & 4,4 & 59 & 0,4 & -59 & 0 & -100 & 7 & -28 & 3 & -6 & 1 & -19 \\
\hline & \multicolumn{2}{|c|}{$\begin{array}{c}\text { Valor implícito } \\
\text { da capoeira em } \\
\text { R } \$ / \text { ha }\end{array}$} & \multicolumn{2}{|c|}{$\begin{array}{l}\text { Valor implícito } \\
\text { da terra em } \mathrm{R} \$\end{array}$} & \multicolumn{2}{|c|}{$\begin{array}{c}\text { Valor implícito da } \\
\text { mão-de-obra na } \\
\text { época de corte e } \\
\text { queima em R\$ } \\
\end{array}$} & \multicolumn{2}{|c|}{$\begin{array}{c}\text { Valor implícito da } \\
\text { mão-de-obra fora } \\
\text { da época de corte e } \\
\text { queima em } \mathrm{R} \$ \\
\end{array}$} & \multicolumn{2}{|c|}{$\begin{array}{l}\text { Área triturada } \\
\text { em ha/ano }\end{array}$} & \multicolumn{2}{|c|}{$\begin{array}{c}\text { Área mecanizada } \\
\text { convencionalme } \\
\text { nte em ha/ano }\end{array}$} \\
\hline & Total & $? \mathrm{em} \%$ & Total & ? em \% & \begin{tabular}{|l|} 
Total \\
\end{tabular} & $? \mathrm{em} \%$ & Total & ? $\mathrm{em} \%$ & Total & ? em \% & Total & ? $\mathrm{em} \%$ \\
\hline 1. Proambiente & 65 & -49 & 26 & -23 & 126 & -31 & 69 & 1 & 3,3 & n.a. & 0 & n.a. \\
\hline $\begin{array}{l}\text { 2. Proambiente modificado } \\
\text { 3. Pagamentos de conservação }\end{array}$ & 183 & 43 & 83 & 143 & 157 & -15 & 99 & 45 & 3,9 & n.a. & 0 & n.a. \\
\hline $\begin{array}{l}\text { ( } \mathrm{R} \$ 160,00 / \text { ha) } \\
\text { 4. Imposto sobre corte e queima }\end{array}$ & 370 & 190 & 52 & 54 & 184 & 0 & 139 & 104 & 2,8 & n.a. & 1,1 & n.a. \\
\hline (R\$300,00/ha) & -23 & -118 & 33 & -3 & 210 & 14 & 145 & 112 & 1,1 & n.a. & 1,2 & n.a. \\
\hline
\end{tabular}


O Proambiente é um programa que visa a promover tecnologias de impactos ambientais reduzidos por meio do fornecimento de créditos subvencionados a agricultores que seguem determinadas regras de produção. O cenário Proambiente mostra o potencial que o programa tem para influenciar positivamente os indicadores de sustentabilidade ecológica - por exemplo, a idade média da capoeira e o seqüestro de carbono. Porém, no regime do cenário, a renda líquida média do estabelecimento cai mais do que 50\%, assim que os incentivos econômicos para a participação são negativos.

O cenário Proambiente modificado mostra que seria possível atingir objetivos ecológicos com um regulamento menos restritivo. No caso, foi permitido o uso de fertilizantes químicos em combinação com uma subvenção de 30\% dos custos da trituração.

Entretanto, uma medida mais efetiva para atingir objetivos relativos à conservação de carbono, da biodiversidade e da cobertura vegetal no estabelecimento modelo seria a aplicação de um imposto sobre o uso de corte e queima para estabelecimentos com acesso ao preparo de terra mecanizado - ou, alternativamente, um pagamento pela conservação para estabelecimentos sem acesso a alternativas tecnológicas. Esses mecanismos são economicamente mais eficientes do que a implementação de padrões de conservação (por exemplo, a reserva legal), porque eles permitem que cada estabelecimento responda de acordo com a sua disposição de fatores de produção.

No caso do imposto, o resultado indica que seria possível aumentar a renda líquida familiar em 9\% por meio da oferta de tecnologia a preço de mercado e ao mesmo tempo dobrar a idade média da vegetação secundária e minimizar os efeitos negativos da mudança tecnológica. Se a oferta de acesso à tecnologia não for uma opção, o modelo indica que pagamentos pela conservação a partir de $\mathrm{R}$ \$100,00/ha incentivam a conservação da vegetação secundária em estabelecimentos típicos da região.

\section{DISCUSSÃO E CONCLUSÕES}

A experiência da modelagem do estabelecimento mostrou que a mecanização do preparo de terra tem alto potencial para aumentar a renda familiar, pelo menos a médio prazo. Porém, especialmente no caso da mecanização convencional, o crescimento econômico é acompanhado de consideráveis emissões de carbono, reduções na qualidade e na cobertura da vegetação secundária; com isso, há risco de danos ambientais não previsíveis.

\footnotetext{
${ }^{5}$ No cenário Proambiente, o estabelecimento recebe um crédito de no máximo R\$5000,00 (juros de 4\%, prazo de 5 anos para pagar 60\% do valor original), o uso de fertilizantes químicos só é permitido em combinação com a trituração (R\$ 860,00/ha). Corte e queima e mecanização não são permitidos.
} 
Uma das alternativas tecnológicas - o sistema agroflorestal (SAF) em combinação com o beneficiamento de frutas - mostrou impactos positivos em indicadores tanto ambientais como econômicos. Mesmo assim, não seria apropriado prescrever o SAF como receita geral para os problemas ambientais da Zona Bragantina, pois o cenário pressupõe o escoamento fácil da produção nos mercados locais e regionais, o que muitas vezes não é possível para produtos perecíveis em áreas remotas. Desse modo, é mais provável que o SAF seja adotado por agricultores com acesso melhor aos mercados urbanos, como mostra a experiência de Castanhal.

Do ponto de vista agronômico, a trituração representa uma alternativa viável, mas, por enquanto, o custo do serviço parece ser uma barreira insuperável para os pequenos agricultores da Zona Bragantina. O ponto de referência para os custos da trituração deveria ser o preço comercial da mecanização convencional. Os dados levantados por Michelotti (2002) mostram que é possível reduzir os custos da trituração (de aproximadamente $\mathrm{R} \$ 860,00$ para $\mathrm{R} \$ 580,00$ ), utilizando um equipamento mais leve, e diminuir a intensidade da trituração. Outras metas para reduzir os custos deveriam ser exploradas para aumentar a competitividade da tecnologia.

Mesmo na ausência de ações governamentais, o modelo indica que o uso da mecanização convencional aumentará futuramente. Foram testados alguns instrumentos da política ambiental que poderiam reduzir os efeitos ambientais negativos da maior difusão dessa tecnologia, sem neutralizar seus efeitos econômicos positivos. Em termos de custos de monitoramento, um sistema combinado de impostos e de pagamentos pela conservação, além de ser economicamente mais eficiente, seria equivalente à implementação da reserva legal e é, conseqüentemente, considerado mais recomendável.

Finalmente, os cenários da implementação do programa Proambiente sugerem que a exclusão do uso de fertilizantes químicos representa uma barreira econômica muito alta para a maioria dos pequenos agricultores da região. As simulações feitas indicam que uma política menos restritiva em relação ao uso de fertilizantes aumentaria a atratividade do programa bem como a chance de atingir os objetivos visados. 


\section{REFERÊNCIAS}

BAAR, R. Vegetationskundliche und ökologische Untersuchungen der Buschbrache in der Feldumlagewirtschaft im östlichen Amazonasgebiet. 1997. 202 f. Tese (PhD) - University of Göttingen, Göttingen, 1997.

BÖRNER, J. A bio-economic model of small-scale farmers' land use decisions and technology choice in the eastern Brazilian Amazon. 2005. 206 p. Não publicado.

DENICH, M. et al. Mechanized land preparation in forest-based fallow systems: The experience from Eastern Amazônia. Agroforestry Systems, [S.l.], v. 61, n. ${ }^{\circ} 1$, p. 91-106, 2004.

HAZELL, P. B. R.; NORTON, R. D. Mathematical programming for economic analysis in agriculture. New York: Macmillan Publishing Co, 1986.

IBGE (Instituto Brasileiro de Geografia e Estatística). Censo agrícola 1995-1996. Disponível em: <http://www.ibge.gov.br> . Acesso em: jan. 2003.

KRUSEMAN, G. Bio-economic household modelling for agricultural intensification. 2000. ... f. Dissertação (Mestrado) - Wageningen University, Wageningen, 2000.

MENDOZA-ESCALANTE, A. Analysis of smallholder agricultural production in the eastern Amazon: empirical evidence and policy prospects for the bragantina region. 2005. 222 S. Thesis (PhD in Agrarwissenschaften) - Universität Bonn, Bonn, Germany, 2005.

MICHELOTTI, F. Vegetação secundária como vegetação de pousio na paisagem agrícola da Amazônia Oriental: função e possibilidades de manipulação. Belém: NAEA, Universidade do Pará, 2002. Relatório final de bolsa de pesquisa. Mimeografado.

RUTHENBERG, H. Farming systems in the tropics. 3.ed. Oxford, UK: Clarendon Press, 1980.

STERMAN, J. D. A sceptic's guide to computer models. In: BARNEY, G. O.; KREUTZER, W. B; GARRETT, M. J. (Ed.). Managing a nation: the microcomputer software catalog. Boulder: Westview Press, 1991. 
WIESENMÜLLER, J. Einfluß landwirtschaftlicher Flächenvorbereitung auf die Dynamik des Wurzelsystems und die oberirdische Regeneration der Sekundärvegetation Ostamazoniens, Pará, Brasilien. 1999. Institute of Agriculture in the Tropics, University of Göttingen, Göttingen, Germany, 1999.

\section{BIBLIOGRAFIA CONSULTADA PARA A MODELAGEM}

BLOCK, A. Göttinger Mähhäcksler Tritucap, und Forstmulcher - nicht brennende Flächenvorbereitung am Beispiel der Zona Bragantina, NordOst-Amazonien, Brasilien. 2004. Thesis (PhD) - Universität Göttingen, Göttingen, 2004.

BORNEMANN, T. The impact of cattle adoption on the labor economy of traditional Smallholders in Eastern Amazonia of Brazil. 2002. Dissertation (M.Sc) - University of Göttingen, Göttingen, 2002,

BÜNEMANN, E. Einfluß von Mulch und mineralischem Dünger auf Zea mays und Vigna unguiculata in der Feldumlagewirtschaft Ostamazoniens. Thesis (Master) - University of Göttingen, Göttingen, 1998.

DENICH, M. et al. The potential and dynamics of carbon sequestration in traditional and modified fallow systems of the Eastern Amazon Region, Brazil. In: LAL, R.; KIMBLE, J. M.; STEWART, B. A. (Ed.). Global climate change and tropical ecosystems. Washington, USA: CRC Press, p. 213229. 2000.

DUARTE, M. L. R. (Ed.). Cultivo da pimenta-do-reino na região Norte. Sistemas de produção 1. Belém: Embrapa Amazônia Oriental, 2003. Disponível em: < http://www.cpatu.embrapa.br> . Acesso em: jan. 2004.

FREIRE, R. et al. Utilização do sistema integrado de diagnose e recomendação (DRIS) na determinação do estado nutricional da pimenta-do-reino em Paragominas, PA. Belém: Embrapa Amazônia Oriental, 1998 (Boletim de Pesquisa, 191).

FREIRE, R. et al. Efeito da adubação NPK na produtividade, nutrição e sanidade da pimenteira-do-reino, em Castanhal, Pará. Belém: Embrapa Amazônia Oriental, 2002 (Boletim de Pesquisa, 10).

IBGE (Instituto Brasileiro de Geografia e Estatística). Produção Agrícola Municipal (1990-2002). Disponível em: <http://www.ibge.gov.br>. Acesso em: jan. 2004. 
IBGE (Instituto Brasileiro de Geografia e Estatística). Censo Demográfico 2000. Disponível em: < http://www.ibge.gov.br> . Acesso em: jan. 2003.

IBGE (Instituto Brasileiro de Geografia e Estatística). Pesquisa de Orçamentos Familiares (2002-2003).

KATO, M. S. A. Fire-free land preparation as an alternative to slashand-burn agriculture in the Bragantina region, eastern Amazon region: crop performance and phosphorous dynamics. Göttingen: Cuvillier Verlag, 1998 (PhD Thesis).

KATO, O. R. Fire-free land preparation as an alternative to slash-andburn agriculture in the Bragantina region, eastern Amazon region: crop performance and nitrogen dynamics. Göttingen: Cuvillier Verlag, 1998 (PhD Thesis).

SANTANA, A. C.; AMIN, M. Cadeias produtivas e oportunidades de negócio na Amazônia. Belém: Universidade da Amazônia, 2002.

SIEGMUND-SCHULTZE, M. Gains from keeping cattle on fallow-based smallholdings in the Eastern Amazon. Göttingen: Cuvillier Verlag, 2002 (PhD Thesis).

SOMMER, R. Water and nutrient balance in deep soils under shifting cultivation with and without burning in the Eastern Amazon. Göttingen: Cuvillier Verlag, 2000 ( PhD Thesis).

SOMMER, R. et al. Carbon storage and root penetration in deep soils under small-farmer land-use systems in the eastern Amazon region, Brazil. Plant and Soil, [S.1.], v. 219, p. 231-241, 2000.

VIEIRA, I. C. Forest succession after shifting cultivation in Eastern Amazônia.. Thesis (PhD) - University of Stirling, Stirling, Scotland, 1996.

VIEIRA, I. C. et al. Classifying successional forests using Landsat spectral properties ecological characteristics in Eastern Amazônia. Remote Sensing of Environment, [S.l.], n. 87, p. 470-481, 2002.

VOSTI, S. A.; CARPENTIER, C. L.; WITCOVER, J. Agricultural intensification by smallholders in the western Brazilian Amazon: from deforestation to sustainable land use. Washington: International Food Policy Research Institute, 2002. 